\title{
PRIMARY TUMORS OF THE CENTRAL NERVOUS SYSTEM. CLINICAL EXPERIENCE AT A THIRD LEVEL CENTER
}

\author{
Alan Hernández-Hernández ${ }^{1,2}$, Ignacio Reyes-Moreno ${ }^{3,4}$, AxayÁcatl GutiérRez-Aceves ${ }^{4}$, \\ Vicente Guerrero-JuÁreZ ${ }^{1}$, José Santos-Zambrano ${ }^{1}$, Manuel López-Martínez ${ }^{1}$, \\ Elvira Castro-Martínez ${ }^{1}$, Bernardo Cacho-Díaz ${ }^{5}$, Javier Avendaño Méndez-Padilla ${ }^{2}$ \\ AND Alberto González-Aguilar ${ }^{1,2,3}$
}

1Emergency Department and 2Department of Neuro-Oncology, Instituto Nacional de Neurología y Neurocirugía, Mexico City; ${ }^{3}$ Neurological Center, The American British Cowdray Medical Center, Mexico City; ${ }^{4}$ Department of Radio-Neurosurgery, Instituto Nacional de Neurología y Neurocirugía, Mexico City; ${ }^{5}$ Department of Neuro-Oncology, Instituto Nacional de Cancerología, Mexico City, Mexico

\begin{abstract}
Background: Central nervous system (CNS) tumors are a group of neoplasms that originate from various cells in the CNS. The increasing incidence and prevalence of this type of tumor in developing countries are striking; however, there are few current studies in Latin America including Mexico estimating the impact of these pathological entities on the general populion. Objective: The objective of the study was to study the characteristics of primary CNS tumors over a period of 52 years. Methods: A review of records from patients with a histopathological diagnosis of CNS neoplasm over a period of 52 years was conducted at a tertiary-care academic medical center. Patients were grouped by sex, age, and the tumor's anatomical location. Results: A sample of 9615 patients with tumor lesions was obtained; $51 \%$ were female, $49 \%$ were male, and their mean age was 42 years. The tumors with the highest prevalence were neuroepithelial tumors (38.6\%), followed by meningeal tumors (22.8\%). Neuroepithelial tumors accounted for $64 \%$ in the group of patients under 40 years of age and $56 \%$ among those above 40 years of age. The most frequently involved location was supratentorial, in $78.9 \%$ of cases. Conclusions: Although retrospective in nature and based on a small sample, this study reports the epidemiology and characteristics of primary brain tumors in the Mexican population. (REV INVES CLIN. 2018;70:177-83)
\end{abstract}

Key words: Central Nervous System. Primary brain tumors. Neuroepithelial tumors. Incidence. Men. Metastatic tumors (Mets).

Corresponding author:

*Alberto González-Aguilar

Instituto Nacional de Neurología y Neurocirugía

Manuel Velasco Suárez

Insurgentes Sur, 3877

Col. La Fama, Del. Tlalpan

C.P. 14269, Mexico City, Mexico

E-mail: albertogonzalez@neurocirugia-innn.com

Received for publication: 08-09-2017

Approved for publication: 22-03-2018

Doi: 10.24875/RIC.18002399 


\section{INTRODUCTION}

Primary tumors of the central nervous system (CNS) encompass a group of neoplasms originating in multiple cell types found in the CNS. These tumors are diagnosed in approximately 52,000 individuals annually in the United States, with a high associated mortality rate $^{1}$. Primary brain tumors account for only $2 \%$ of all tumors; in the United States, their estimated incidence is $28.6 / 100,000$ adults $^{2}$. Most tumors have a high degree of morbidity and mortality ${ }^{3}$, as in the cases of anaplastic astrocytoma and glioblastoma, in which the 5 -year survival rates are $29.7 \%$ and $5.5 \%$, respective$1 y^{4}$. Risk factors that have been associated with primary brain tumors include hereditary syndromes and ionizing radiation with therapeutic or diagnostic purposes, and other sources 5 . Headache is the most common clinical manifestation of brain tumors, and in half of the patients, the worst symptom ${ }^{6}$; seizures are also one of the most common presentations but are more frequent in cases of primary tumors than in metastatic lesions ${ }^{7,8}$. Primary malignant brain tumors are a common concern among medical investigators not only because of their poor prognosis but also because these entities result in a large proportion of cases with neurological dysfunction, as well as decreased psychological health and quality of life 9 . In Mexico, only a few institutions have conducted research on the epidemiology of this entity, although their sample sizes were not large ${ }^{10,11}$. The purpose of this study was to describe the prevalence of primary brain tumors, as well as the subtypes that most frequently affect the population of patients treated in a tertiary care neurology and neurosurgery institute, over a period of 52 years.

\section{PATIENTS AND METHODS}

This is a retrospective, descriptive study of patients over 18 years of age, diagnosed with a CNS tumor and elective treated by neurosurgical resection; after the histopathological diagnosis, patients were followed at the National Institute of Neurology and Neurosurgery Manuel Velasco Suárez in Mexico. The study includes all patients fulfilling the inclusion criteria over a 52-year period. The data obtained for the study were collected from the hospital's chart database and included patients with a CNS tumor requiring neurosurgical intervention and whose histopathological results were available.
The group and histological diagnosis were established based on the WHO international system for the classification of CNS tumors, created in $2007^{12}$. The classification includes 7 groups: neuroepithelial tumors, tumors of cranial and paraspinal nerves, meningeal tumors, hematopoietic tumors and lymphoma, germ cell tumors, tumors of the sellar region, and metastatic tumors.

Statistical analysis was based on qualitative variables (sex, tumor's anatomical site, and histological group) and quantitative variables (age). Frequency, percentage, measures of frequency, and central tendency measures were analyzed using descriptive statistics.

\section{RESULTS}

During the period studied, 9,615 tumor lesions were diagnosed and grouped in terms of their degree of malignancy, histopathological type, and the most frequent anatomical location. Tumors were more frequent in females (51\%) than in males ( $49 \%$ ), and the mean age at diagnosis in the entire cohort was 42 years.

The group of neuroepithelial tumors was the most common (38.6\% of cases), followed by meningeal tumors (22.8\%), tumors of the sellar region (20.2\%), cranial and paraspinal nerves (6.5\%), metastatic tumors (4.1\%), lymphomas and hematopoietic tumors (1.8\%), and germ cell tumors (0.7\%). According to the histology subtype, the mean age at diagnosis was: astrocytomas, 40 years; glioblastomas, 46.4 years; ependymoma, 37 years; medulloblastoma, 29 years; meningioma, 46.8 years; lymphoma, 47.5 years; schwannoma, 40.5 years; and pituitary adenoma, 41 years. The mean age based on the histological group was 38.7 years for neuroepithelial tumors, 36.7 years for cranial and paraspinal nerves tumors, 41.7 years for meningeal tumors, 51.8 years for lymphoma and hematopoietic tumors, 36.5 years for sellar region tumors, 21.5 years for germ cell tumors, and 40 years for metastases.

We divided the sample of patients into two groups, those over age 40 and those under age 40 , to determine the frequency with which brain tumors develop since they seem to appear at a younger age in the Mexican population. We found that the most 
Figure 1. Percentage of patients over age 40 and its correlation with the histopathological tumor group.

NT: neuroepithelial tumors; MT: meningeal tumors; TC and PN: tumors of cranial and paraspinal nerves; GT: germ cell tumors; Mets: metastases; HT and L: hematopoietic tumors and lymphoma.

Over 40 years old

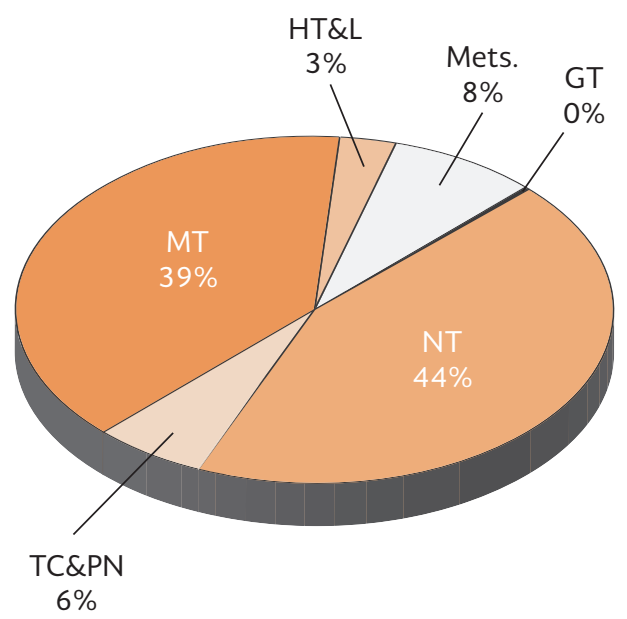

prevalent tumors in patients older than 40 years were meningioma in the first place, followed by glioblastoma, and pituitary adenomas in the third place.

In patients under 40 years of age, the most prevalent tumor was a pituitary adenoma, followed by astrocytoma and meningioma.

Among tumors of the sellar region, pituitary adenomas accounted for $94.5 \%$ of all cases. Among neuroepithelial tumors, glioblastoma represented $42.5 \%$ of cases; astrocytomas $32.7 \%$; oligoastrocytomas $7.1 \%$; medulloblastomas $6.7 \%$; ependymomas $4.1 \%$, and oligodendrogliomas $3.2 \%$. Among meningeal tumors, meningiomas accounted for $77.3 \%$ of all meningeal tumors; the rest were mesenchymal tumors. Details are shown in figures 1 and 2 .

According to the degree of malignancy, Grade I tumors were the most prevalent, followed by those classified as Grade II (Fig. 3).

In the group of other tumors, which included 467 patients, the most frequent lesions were epidermal cysts, dermoid cysts, arachnoid cysts, osseous cysts, and sebaceous cysts, and chondromas, hamartomas, chordomas, and glomus tumors, among others.
Figure 2. Percentage of patients under age 40 and its correlation with the histopathological tumor group.

NT: Neuroepithelial tumors; MT: meningeal tumors; TC and $\mathrm{PN}$ : tumors of cranial and paraspinal nerves; GT: germ cell tumors; Mets: metastases; HT and L: hematopoietic tumors and lymphoma.

Under 40 years old

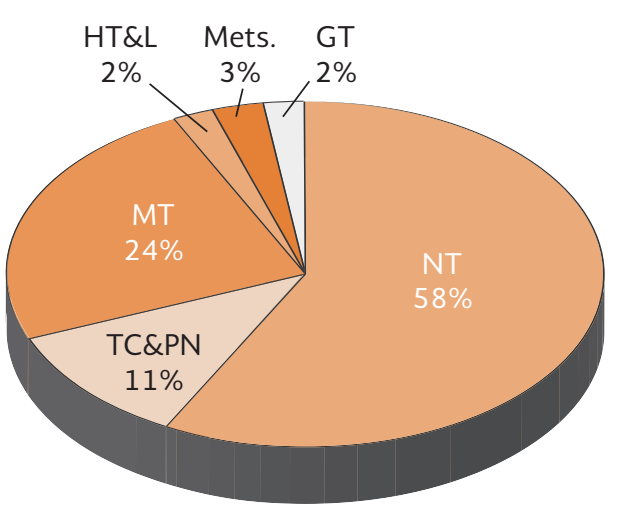

Figure 3. Degree of malignancy (the WHO classification 2007). ${ }^{13}$

Degree of malignancy

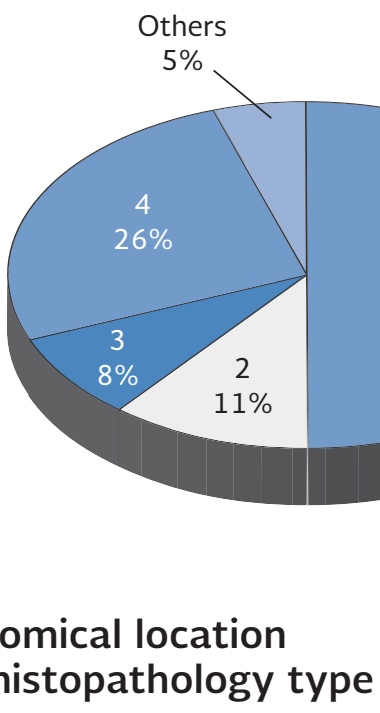

The supratentorial region was the most affected, and the majority of tumors were located in the sellar region, followed by the frontal lobe. The tumors that were most frequently located in the infratentorial were meningeal tumors, followed by cranial and paraspinal tumors, and neuroepithelial tumors. 
Table 1. Tumor groups and correlation with location

\begin{tabular}{|c|c|c|c|c|c|c|c|c|c|}
\hline Location & $\begin{array}{c}\text { MT } \\
\mathrm{n}=2195 \\
(\%)\end{array}$ & $\begin{array}{c}\text { NT } \\
n=3849 \\
(\%)\end{array}$ & $\begin{array}{c}\text { TSR } \\
\mathrm{n}=1956 \\
(\%)\end{array}$ & $\begin{array}{c}\text { TC\&PN } \\
\mathrm{n}=577 \\
(\%)\end{array}$ & $\begin{array}{c}\text { GT } \\
n=40 \\
(\%)\end{array}$ & $\begin{array}{c}\mathrm{HT} \text { and } \mathrm{L} \\
\mathrm{n}=136 \\
(\%)\end{array}$ & $\begin{array}{c}\text { Mets. } \\
n=312 \\
(\%)\end{array}$ & & $\begin{array}{l}\text { Total } \\
=9065 \\
(\%)\end{array}$ \\
\hline \multicolumn{10}{|l|}{ Supratentorial } \\
\hline Frontal & $\begin{array}{c}4 \\
(0.18)\end{array}$ & $\begin{array}{c}1173 \\
(30.4)\end{array}$ & - & $\begin{array}{c}2 \\
(0.34)\end{array}$ & $\begin{array}{c}4 \\
(10)\end{array}$ & $\begin{array}{c}38 \\
(27.9)\end{array}$ & $\begin{array}{c}91 \\
(29.1)\end{array}$ & (2) & $\begin{array}{l}1312 \\
(14.4)\end{array}$ \\
\hline Temporal & $\begin{array}{c}5 \\
(0.22)\end{array}$ & $\begin{array}{c}894 \\
(23.2)\end{array}$ & - & $\begin{array}{c}6 \\
(1.0)\end{array}$ & $\begin{array}{c}1 \\
(2.5)\end{array}$ & $\begin{array}{c}13 \\
(9.5)\end{array}$ & $\begin{array}{c}44 \\
(14.1)\end{array}$ & $\frac{\dot{\theta}}{c}$ & $\begin{array}{c}963 \\
(10.6)\end{array}$ \\
\hline Parietal & $\begin{array}{c}3 \\
(0.13)\end{array}$ & $\begin{array}{c}720 \\
(18.7)\end{array}$ & - & $\begin{array}{c}1 \\
(0.17)\end{array}$ & $\begin{array}{c}6 \\
(15)\end{array}$ & $\begin{array}{c}14 \\
(10.2)\end{array}$ & $\begin{array}{c}59 \\
(18.9)\end{array}$ & & $\begin{array}{l}803 \\
(8.8)\end{array}$ \\
\hline Occipital & $\begin{array}{c}2 \\
(0.09)\end{array}$ & $\begin{array}{c}436 \\
(11.3)\end{array}$ & - & $\begin{array}{c}10 \\
(1.7)\end{array}$ & $\begin{array}{c}2 \\
(5)\end{array}$ & $\begin{array}{c}8 \\
(5.8)\end{array}$ & $\begin{array}{c}14 \\
(4.4)\end{array}$ & 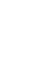 & $\begin{array}{c}472 \\
(5.2)\end{array}$ \\
\hline Intraventricular & $\begin{array}{c}55 \\
(2.5)\end{array}$ & $\begin{array}{l}166 \\
(4.3)\end{array}$ & - & $\begin{array}{c}2 \\
(0.34)\end{array}$ & $\begin{array}{c}6 \\
(15)\end{array}$ & $\begin{array}{c}5 \\
(3.6)\end{array}$ & $\begin{array}{c}3 \\
(0.96)\end{array}$ & $\begin{array}{l}\frac{4}{\circ} \\
\frac{5}{0}\end{array}$ & $\begin{array}{l}237 \\
(2.6)\end{array}$ \\
\hline Sellar & $\begin{array}{l}130 \\
(5.9)\end{array}$ & $\begin{array}{c}6 \\
(0.15)\end{array}$ & $\begin{array}{l}1956 \\
(100)\end{array}$ & - & $\begin{array}{c}11 \\
(27.5)\end{array}$ & $\begin{array}{c}1 \\
(0.7)\end{array}$ & - & 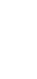 & $\begin{array}{l}2104 \\
(23.2)\end{array}$ \\
\hline Parasagittal & $\begin{array}{c}281 \\
(12.8)\end{array}$ & - & - & - & - & - & $\begin{array}{c}1 \\
(0.32)\end{array}$ & $\frac{1}{c}$ & $\begin{array}{c}282 \\
(3.1)\end{array}$ \\
\hline Convexity & $\begin{array}{c}685 \\
(31.2)\end{array}$ & $\begin{array}{c}3 \\
(0.07)\end{array}$ & - & - & - & - & $\begin{array}{c}1 \\
(0.32)\end{array}$ & : & $\begin{array}{l}689 \\
(7.6)\end{array}$ \\
\hline Corpus callosum & - & $\begin{array}{c}76 \\
(2.0)\end{array}$ & - & - & $\begin{array}{c}2 \\
(5)\end{array}$ & $\begin{array}{c}12 \\
(8.8)\end{array}$ & - & 흔 & $\begin{array}{c}90 \\
(0.9)\end{array}$ \\
\hline \multicolumn{10}{|l|}{ Infratentorial } \\
\hline Cerebellum & $\begin{array}{c}89 \\
(4.0)\end{array}$ & $\begin{array}{l}203 \\
(5.2)\end{array}$ & - & - & - & $\begin{array}{c}8 \\
(5.8)\end{array}$ & $\begin{array}{c}45 \\
(14.4)\end{array}$ & 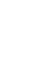 & $\begin{array}{c}345 \\
(3.8)\end{array}$ \\
\hline CPA & $\begin{array}{c}114 \\
(5.19)\end{array}$ & $\begin{array}{c}3 \\
(0.07)\end{array}$ & - & $\begin{array}{c}326 \\
(56.4)\end{array}$ & - & $\begin{array}{c}1 \\
(0.7)\end{array}$ & $\begin{array}{c}2 \\
(0.6)\end{array}$ & $\frac{5}{3}$ & $\begin{array}{c}446 \\
(4.9)\end{array}$ \\
\hline Skull base & $\begin{array}{c}311 \\
(14.1)\end{array}$ & $\begin{array}{c}52 \\
(1.3)\end{array}$ & - & $\begin{array}{c}41 \\
(7.1)\end{array}$ & $\begin{array}{c}3 \\
(7.5)\end{array}$ & $\begin{array}{c}12 \\
(8.8)\end{array}$ & $\begin{array}{c}11 \\
(3.5)\end{array}$ & 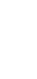 & $\begin{array}{c}430 \\
(4.7)\end{array}$ \\
\hline Tentorium & $\begin{array}{l}132 \\
(6.0)\end{array}$ & - & - & - & - & - & $\begin{array}{c}1 \\
(0.32)\end{array}$ & ర్ & $\begin{array}{c}133 \\
(1.4)\end{array}$ \\
\hline Sphenoid wing & $\begin{array}{c}162 \\
(7.3)\end{array}$ & - & - & - & - & $\begin{array}{c}1 \\
(0.7)\end{array}$ & - & $\frac{0}{c}$ & $\begin{array}{c}163 \\
(1.7)\end{array}$ \\
\hline Foramen magnum & $\begin{array}{c}51 \\
(2.3)\end{array}$ & $\begin{array}{c}1 \\
(0.02)\end{array}$ & - & - & - & - & - & o & $\begin{array}{c}52 \\
(0.5)\end{array}$ \\
\hline Medullary & $\begin{array}{c}171 \\
(7.7)\end{array}$ & $\begin{array}{l}116 \\
(3.0)\end{array}$ & - & $\begin{array}{c}189 \\
(32.7)\end{array}$ & $\begin{array}{c}5 \\
(12.5)\end{array}$ & $\begin{array}{c}23 \\
(16.9)\end{array}$ & $\begin{array}{c}40 \\
(12.8)\end{array}$ & $\frac{1}{0}$ & $\begin{array}{l}544 \\
(6)\end{array}$ \\
\hline
\end{tabular}

NT: neuroepithelial tumors; MT: meningeal tumors; TSR: tumors of the sellar region; TC and PN: tumors of cranial and paraspinal nerves; GT: germ cell tumors; Mets: metastases; HT and L: hematopoietic tumors and lymphoma; CPA: cerebellopontine angle.

Among the meningeal tumors, 54\% were infratentorial, and $90.3 \%$ of the neuroepithelial tumors were supratentorial.

Medullary compromise was most frequently associated with spinal nerve tumors, which represented $38.2 \%$ of cases, followed by meningiomas and ependymomas. Spinal cord involvement was observed in $6.1 \%$ of tumors, predominantly as a result of schwannomas, followed by neurofibromas. In terms of tumor location, meningiomas were most frequently situated on the convexity. Astrocytomas and glioblastomas were most frequently detected in the frontal lobe. Metastatic lesions were more frequent in the parietal lobe followed by the cerebellum and temporal lobe, and ependymomas were most common in the medullary region. Table 1 shows the location of the tumors according to the histopathological diagnosis group and the affected region. However, only 9065 cases of the total cohort are shown on this table because it does not include 467 tumor lesions, which corresponded to the other tumors, shown in table 2, and 83 tumors in which the location was not specified in the records. 
Table 2. Histopathological subtype of 9615 cases of primary brain tumors and metastases over a 52-year period

\begin{tabular}{|c|c|c|c|c|}
\hline Type of brain tumors & $\begin{array}{c}n=9615 \\
(\%)\end{array}$ & $\begin{array}{c}M, n=4690 \\
(\%)\end{array}$ & $\begin{array}{c}F, n=4925 \\
(\%)\end{array}$ & $\begin{array}{l}\text { Mean } \\
\text { age }\end{array}$ \\
\hline \multicolumn{4}{|l|}{ Neuroepithelial tumors } & $\stackrel{\sigma}{\varepsilon}$ \\
\hline Astrocytomas & $1220(12.6)$ & $677(14.4)$ & $543(11)$ & 40 \\
\hline Glioblastoma & $1586(16.4)$ & $941(20)$ & $645(13)$ & 46.4 \\
\hline Ependymoma & $154(1.6)$ & $78(1.6)$ & $76(1.5)$ & 37 \\
\hline Oligodendroglioma & $121(1.2)$ & $63(1.3)$ & $58(1.17)$ & 42 \\
\hline Oligoastrocytoma & $265(2.7)$ & $144(3.0)$ & $121(2.4)$ & 40.3 \\
\hline Choroid plexus tumors & $68(0.7)$ & $27(0.57)$ & $41(0.8)$ & 34.5 \\
\hline \multicolumn{4}{|l|}{ Embryonal tumors } & 를 \\
\hline Medulloblastoma & $253(2.6)$ & $158(3.3)$ & $95(1.9)$ & 29 \\
\hline PNET & $6(0.06)$ & $2(0.04)$ & $4(0.08)$ & 45.5 \\
\hline Neuroblastoma & $15(0.15)$ & $8(0.17)$ & $7(0.14)$ & 38.2 \\
\hline \multicolumn{4}{|l|}{ Neuroglial tumors } & $\cdot \frac{0}{n}$ \\
\hline $\begin{array}{l}\text { Ganglioglioma/ } \\
\text { paraganglioma }\end{array}$ & $15(0.15)$ & $5(0.10)$ & $10(0.20)$ & 40 \\
\hline Astroblastoma & $18(0.18)$ & $12(0.25)$ & $6(0.12)$ & 33 \\
\hline \multicolumn{4}{|l|}{$\begin{array}{l}\text { Tumors of cranial } \\
\text { and paraspinal nerves }\end{array}$} & $\frac{ \pm}{ \pm}$ \\
\hline Schwannoma & $540(5.6)$ & $235(5.0)$ & $305(6.19)$ & 40.5 \\
\hline Neurofibroma & $86(0.8)$ & $37(0.78)$ & $49(0.99)$ & 33.3 \\
\hline \multicolumn{4}{|l|}{ Meningeal tumors } & $\stackrel{0}{\epsilon}$ \\
\hline Meningioma & $1925(20)$ & $591(12.6)$ & $1334(27)$ & 46.8 \\
\hline \multicolumn{4}{|l|}{ Mesenchymal } & $\overrightarrow{0}$ \\
\hline Hemangioblastoma & $175(1.8)$ & $107(2.2)$ & $68(1.3)$ & 38 \\
\hline Hemangiopericytoma & $62(0.6)$ & $23(0.49)$ & $39(0.79)$ & 44.8 \\
\hline Sarcoma & $33(0.3)$ & $11(0.23)$ & $22(0.44)$ & 45 \\
\hline Histiocytoma & $5(0.05)$ & $3(0.06)$ & $2(0.04)$ & 35.2 \\
\hline $\begin{array}{l}\text { Hematopoietic tumors } \\
\text { and lymphoma }\end{array}$ & $174(1.8)$ & $96(2.04)$ & $78(1.5)$ & $\begin{array}{l}51.8 \\
=\end{array}$ \\
\hline \multicolumn{4}{|l|}{ Tumors of sellar region } & $\frac{1}{0}$ \\
\hline Craniopharyngioma & $200(2.0)$ & $108(2.3)$ & $92(1.8)$ & 32 \\
\hline Pituitary adenoma & $1750(18.1)$ & $876(18.6)$ & $874(17.7)$ & 41 \\
\hline Germ cell tumors & $75(0.7)$ & $60(1.2)$ & $15(0.30)$ & 21.5 \\
\hline Metastases & $402(4.1)$ & $221(4.7)$ & $181(3.6)$ & 40 \\
\hline Other tumors & $467(4.8)$ & $204(4.3)$ & $263(5.3)$ & - \\
\hline
\end{tabular}

$\mathrm{N}$ (number), \% (percentage), M (male), F (female), PNET: primary neuroectodermal tumor.

\section{Brain metastases}

Overall, there were 402 patients with brain metastases registered. In order of frequency, metastases originated in the lung $40.5 \%$, breast $14.6 \%$, kidney 9.9\%, and melanoma $9.4 \%$ (Table 3).

At the medullary level, metastases were most common in the thoracic and cervical regions followed by the lumbosacral area.

\section{DISCUSSION}

Tumors of the CNS are a common cause of consultation in the departments of neurology and neurosurgery in many institutions. The type of tumor determines its specific treatment as well as the survival rate. Survival tends to vary according to the type of lesion. An example of this is the poor survival rate in tumors of the posterior fossa: $26 \%$ at 5 years and $7 \%$ if they compromise the brain stem ${ }^{13}$. 
Table 3. Primary metastases according to gender

\begin{tabular}{lccc}
\hline Type of metastases & $\mathrm{n}(\%)$ & Male (\%) & Female (\%) \\
\hline Total metastases & $\mathrm{n}=402(100)$ & $\mathrm{n}=167(41.5)$ & $\mathrm{n}=235(58.4)$ \\
Lung & $163(40.5)$ & $44(26.3)$ & $119(50.6)$ \\
Breast & $59(14.6)$ & $23(13.7)$ & $36(15.3)$ \\
Kidney & $40(9.9)$ & $26(15.7)$ & $14(5.9)$ \\
Melanoma & $38(9.4)$ & $18(10.7)$ & $20(8.5)$ \\
Thyroid & $10(2.4)$ & $6(3.5)$ & $4(1.7)$ \\
Embryonal carcinoma & $8(1.9)$ & $5(2.39)$ & $4(1.7)$ \\
Prostate & $5(1.2)$ & $2(1.19)$ & - \\
Digestive & $4(0.9)$ & $1(0.59)$ & $2(0.85)$ \\
Sarcoma & $3(0.7)$ & $2(1.19)$ & $2(0.85)$ \\
Testicular & $2(0.4)$ & - & - \\
Bladder & $2(0.4)$ & $1(0.59)$ & $2(0.85)$ \\
Chondrosarcoma & $2(0.4)$ & - & $1(0.4)$ \\
Ovary & $1(0.2)$ & - & $1(0.4)$ \\
Choriocarcinoma & $1(0.2)$ & $17(10.1)$ & $1(0.4)$ \\
Unclassified & $27(6.7)$ & $17(10.1)$ & $10(4.2)$ \\
Unknown primary & $33(8.2)$ & $1(0.59)$ & $16(6.8)$ \\
Other & $4(0.9)$ & & $3(1.27)$ \\
\hline
\end{tabular}

The main objective of this study was to provide an understanding of how tumors behave in the Mexican population and how they compare to other series. This series shows that in the adult population studied for a primary brain tumor lesion, the most prevalent tumor was meningioma (20\%), and the group of tumors with the highest prevalence was the neuroepithelial tumors ( $38.5 \%)$. In the series by CBTRUS in the United States, the most prevalent tumor also was meningioma, accounting for $35.5 \%$ in 2012 and, later, $37 \%$ in $2016^{4,14}$. In the European series as well as in those from France and Greece, neuroepithelial tumors were the most prevalent, with $53.9 \%$ for the French, and $33.3 \%$ for the Greek populations. In Asia, the series reported by China showed that neuroepithelial tumors had a prevalence of $38 \%$ and meningeal tumors of $36 \%$. However, in Japan, the tumors with the highest prevalence were those of the meninges, with a $38.2 \%$ prevalence ${ }^{14,15}$. Among studies from Latin America, the study by Anaya et al. in Mexico and the one conducted in Colombia, agreed that the most prevalent brain tumor was meningioma (33\% and $50 \%$, respectively) (Table 2$)^{13,16}$.

Cerebral metastases comprise the majority of intracranial tumors in the adult population, with an incidence between $8.5 \%$ and $9.6 \%$, while the literature has reported an average incidence of $10-20 \%$ in all patients with cancer. This incidence tends to vary depending on the primary lesion. In order of frequency, metastases originate mostly from lung cancer, renal cell carcinoma, melanoma, and breast cancer. Although lung and breast cancers are more prevalent, the one with the greatest risk of invading the CNS is melanoma ${ }^{17,18}$.

In order of frequency, tumors that originate at the medullary level are meningiomas, spinal nerve tumors, and ependymomas ${ }^{19}$.

In medullary tumors, metastatic invasion hinges on hematogenous, lymphatic, and contiguous dissemina$\operatorname{tion}^{20}$. Metastases in the thoracic and cervical regions occur more commonly than in the thoracolumbar region. In our series, as in the study by Payer et al., thoracic and cervical metastases were the most common, followed by those in the lumbosacral region ${ }^{21}$.

The mean age at diagnosis of glioblastoma is 64 years; it is more frequent in men than in women, and it tends to be more common in Caucasians than in the black population ${ }^{4,11}$. In Mexico, a study by LópezGonzález et al. showed that the mean age of glioblastoma diagnosis was 51 years and represented $9 \%$ of the 1,776 patients included in their study; it was also more frequent in male patients ${ }^{10}$. 
Table 4. Comparison between international series of primary brain tumor prevalence (\%)

\begin{tabular}{|c|c|c|c|c|c|c|c|c|c|c|}
\hline Country & Author & Period & NT & $\mathrm{MT}$ & TSR & TC\&PN & GT & Mets. & 2 & HT\&L \\
\hline China & Chen et al. & $1950-2009$ & 38 & 36.5 & 4.1 & 13.3 & 1.3 & 5.1 & 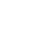 & 1.7 \\
\hline USA & CBTRUS. & 2005-2009 & 29 & 35.5 & 15 & 8.3 & 0.5 & - & $\xi$ & 2.2 \\
\hline USA & CBTRUS. & $2009-2013$ & 29.2 & 37 & 16.7 & 8.2 & 0.3 & - & 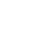 & 2 \\
\hline France & Rigau et al. & 2004-2008 & 53.9 & 28.8 & 2.2 & 8.4 & 3 & - & (C) & 3.2 \\
\hline Japan & Nakamura et al. & 1989-2008 & 20 & 38.2 & 19.3 & 10.2 & 1.2 & - & & 3.6 \\
\hline Colombia & Ramos et al. & 2001-2006 & 65.4 & 32.3 & - & - & 0.3 & - & $\stackrel{\square}{\frac{1}{\alpha}}$ & - \\
\hline Mexico & Anaya et al. & $1993-2013$ & 23.6 & 33.2 & 18.2 & 13.2 & 0 & 8.8 & $\underline{\underline{\underline{n}}}$ & 3 \\
\hline Mexico & Hernández A. et al. & $1964-2016$ & 38.6 & 22.8 & 20.2 & 6.5 & 0.7 & 4.1 & $\frac{0}{3}$ & 1.8 \\
\hline
\end{tabular}

NT: neuroepithelial tumors; MT: meningeal tumors; TSR: tumors of the sellar region; TC and PN: tumors of cranial and paraspinal nerves; GT: germ cell tumors; Mets: metastases; HT and L: hematopoietic tumors and lymphoma.

In a study conducted in Korea, glioblastoma represented $5.9 \%$ of all CNS tumors, and $30.4 \%$ of neuroepithelial tumors were diagnosed at age $55^{22}$. In our series, 1,586 patients had glioblastoma, appearing at a mean age of 46.4 years, and it also was more frequent in males. Hence, in our population, this type of tumors presents at an early age compared with that reported in the literature.

One of the objectives of this study was to understand how tumors of the CNS behave in our population, compared to other Latin American, North American, and international series. Table 4 shows the differences between our population and those reported in the literature. However, these are only single-center statistics and collaboration with other institutions is pivotal to increase our knowledge on these tumors at the national level.

\section{REFERENCES}

1. Kasper DL, Fauci AS, Hauser SL, Longo DL, Jameson JL, Loscalzo J, editors. Harrison's Principles of Internal Medicine. Primary and Metastatic Tumors of the Nervous System. $19^{\text {th }}$ ed., Vol. 118. New York: McGraw Hill Education Medical; 2015. p. 598-607.

2. Ostrom QT, Gittleman H, Fulop J, et al. CBTRUS statistical report: primary brain and central nervous system tumors diagnosed in the United States in 2008-2012. Neuro Oncol. 2015;17 Suppl 4:41-462.

3. Ostrom QT, Gittleman H, Liao P, et al. CBTRUS statistical report: primary brain and central nervous system tumors diagnosed in the United States in 2007-2011. Neuro Oncol. 2014;16 Suppl 4:41-63.

4. Ostrom QT, Gittleman H, Xu J, et al. CBTRUS statistical report: primary brain and other central nervous system tumors diagnosed in the United States in 2009-2013. Neuro Oncol. 2016; 18:51-575

5. Wrensch M, Minn Y, Chew T, Bondy M, Berger MS. Epidemiology of primary brain tumors: current concepts and review of the literature. Neuro Oncol. 2002;4:278-99.
6. Forsyth PA, Posner JB. Headaches in patients with brain tumors: a study of 111 patients. Neurology. 1993;43:1678-83.

7. Pace A, Bove L, Innocenti P, et al. Epilepsy and gliomas: incidence and treatment in 119 patients. J Exp Clin Cancer Res. 1998 17:479-82.

8. Çetin ÖE, İsler C, Uzan M, Özkara Ç. Epilepsy-related brain tumors. Seizure. 2017;44:93-7.

9. Naser RK, Hassan AA, Shabana AM, Omar NN. Role of magnetic resonance spectroscopy in grading of primary brain tumors. Egypt J Radiol Nucl Med. 2016;47:577-84.

10. Lopez-Gonzalez, Sotelo J. Brain tumors in Mexico: characteristics and prognosis of glioblastoma. Surg Neurol. 2000;53:157-62.

11. Alifieris C, Trafalis DT. Glioblastoma multiforme: pathogenesis and treatment. Pharmacol Ther. 2015;152:63-82.

12. Louis DN, Ohgaki H, Wiestler OD, et al. The 2007 WHO classification of tumours of the central nervous system. Acta Neuropathol. 2007;114:97-109.

13. Anaya-Delgadillo G, Juambelz-Cisneros PP, Fernández-Alvarado B, Pazos-Gómez F, Velasco-Torre A, Revuelta-Gutiérrez R. Prevalence of central nervous system tumors and histological identification in the operated patient: 20 years of experience. Cir Cir. 2016:84:447-53.

14. Dolecek TA, Propp JM, Stroup NE, Kruchko C. CBTRUS statistical report: primary brain and central nervous system tumors diagnosed in the United States in 2005-2009. Neuro Oncol. 2012;14 Suppl 5:51-49.

15. Nakamura H, Makino K, Yano S, Kuratsu J, Kumamoto Brain Tumor Research Group. Epidemiological study of primary intracranial tumors: a regional survey in Kumamoto prefecture in southern japan--20-year study. Int J Clin Oncol. 2011. 16:314-21.

16. Ramos-Clason EC, Tuñón-Pitalua MC, Rivas-Muñoz FA, VelozaCabrera LA. Primary central nervous system tumours reported in cartagena, 2001-2006. Rev Salud Publica (Bogota). 2010; 12:257-67.

17. Yanagihara TK, Lee A, Wang TJC. Quantitative analysis of the spatial distribution of metastatic brain lesions. Tomography. 2017;3:16-22.

18. Shonka N, Venur VA, Ahluwalia MS. Targeted treatment of brain metastases. Curr Neurol Neurosci Rep. 2017;17:37.

19. Duong LM, McCarthy BJ, McLendon RE, et al. Descriptive epidemiology of malignant and nonmalignant primary spinal cord, spinal meninges, and cauda equina tumors, united states, 20042007. Cancer. 2012;118:4220-7.

20. Gilbert RW, Kim JH, Posner JB. Epidural spinal cord compression from metastatic tumor: diagnosis and treatment. Ann Neurol. 1978;3:40-51.

21. Payer S, Mende KC, Westphal M, Eicker SO. Intramedullary spinal cord metastases: an increasingly common diagnosis. Neurosurg Focus. 2015;39:E15.

22. Lee $\mathrm{CH}$, Jung $\mathrm{KW}$, Yoo $\mathrm{H}$, Park $\mathrm{S}$, Lee $\mathrm{SH}$. Epidemiology of primary brain and central nervous system tumors in Korea. J Korean Neurosurg Soc. 2010;48:145-52. 